\title{
Yellow Oleander (Thevetia peruviana) Seed Poisoning (YOSP) in the Batticaloa District, Sri Lanka: Is related with Fruiting Season?
}

\author{
Madhura, $\mathbf{J}^{1}$, Arulnithy, $\mathbf{K}^{1}$, Mathiventhan, $\mathbf{U}^{2}$, Mathiventhan, $\mathrm{T}^{2}$ \\ ${ }^{1}$ Department of Cardiology, Teaching Hospital, Batticaloa \\ ${ }^{2}$ Department of Botany, Eastern University, Sri Lanka \\ madhurajayasingam@gmail.com, karulnithy@yahoo.co.uk,umaramanip@yahoo.com, \\ tmathiventhan@gmail.com
}

\begin{abstract}
Yellow oleander seed poisoning (YOSP) has been reported as one of the means to commit suicide in Batticaloa district. This study was an attempt to find relation between the YOSP and fruiting season of yellow oleander. A total number of 1076 patients admitted due to YOSP during November 2011 to March 2016 (during 52 months). More than $80 \%$ were females with the age range between 20 and 35 years. YOSP is higher during the dry season where the rainfall was below $400 \mathrm{~mm}$ during the study period and the admission was higher in May, every year. The study unable to establish a relationship between fruiting season of yellow oleander and the YOSP, because yellow oleander produces fruits throughout the year, irrespective of the dry and rainy seasons.
\end{abstract}

Keywords: Seed poisoning, season.

\section{INTRODUCTION}

Thevetia peruvina is prevalent in South Asian countries, especially in India and Sri Lanka [1] (Common name - Lucky nut, Suicide tree, Milk bush (English); Manchal alari (Tamil), Kaneru (Sinhala). Thevetia peruvina is toxic to most vertebrates as they contain cardiac glycosides. TP contains a milky sap, Latex, (generally all parts of the plant) that consists of a compound called "Thevetin". Thevetin is used as a heart stimulant but its natural form is extremely poisonous [2]. Thevetin is a cardenoloides called Thevetin A and Thevetin B (Cerebroside), others include Peruvoside, Neriifolin, Thevetoxin and Ruvoside. They produce gastric and cardio toxic effects [3],[4],[5]. They also reported that the antidotes for treatment may include oral administration of activated charcoal.

Ibiyemi [6] reported that Thevetia peruviana plants produce more than 400-800 fruits per annum depending on the rainfall and plant age. The author stated that the long break in rainfall experienced in July and August in Ilorin and Edidi in 1996 caused a significant statistical decrease in the number of fruits each plant produced that year.

Yellow oleander poisoning has been described as an epidemic and largely affects Sri Lanka [7]; the country remains to have one the highest suicide rates in the world and the trend of oleander poisoning has been difficult to halt due to the lack of resources to manage the problem, reported by [8]. Intentional and accidental human poisoning has been reported at the Teaching Hospital of Batticaloa [5],[8]. YOSP are common among young females at the Eastern Province of Sri Lanka during 2011 [9]. They also reported that the cardiac toxicity develops within $24 \mathrm{hrs}$ of ingestion of Yellow oleander seeds and the risk of toxicity has negative correlation with number of seeds.

\subsection{Mechanism of Toxicity}

Ingestion of seeds causing severe problem (up to lethal), due to higher content of glycosides in Thevetin, than the other parts of the plant. Rezvi [10] reported that the percentage of glycosides existed in the seeds is 4.800 followed by leaf, latex and fruit of yellow oleander as 0.070, 0.045 and 0.036 respectively. Barceloux [11] reported that "The cardiac glycosides inhibit the transmembrane $\mathrm{Na}^{+} / \mathrm{K}^{+}$ATPase pump, and this action produces increased intercellular concentrations of $\mathrm{Ca}^{++}$and $\mathrm{Na}^{+}$. 
Subendocardial and perivascular hemmorage along with focal myocardial edema are the common pathological findings during examination of fatal cases of yellow oleander poisoning".

\subsection{Description of Yellow Oleander}

Thevetia peruviana is a tropical, evergreen, small ornamental tree/shrub grown in gardens and road sides, which grows to about $1.5-2.3 \mathrm{~m}$ height. The leaves are spirally arranged, linear and about 13$15 \mathrm{~cm}$ in length [12]. Flowers are bright yellow and funnel-shaped, sometimes fragrant, with five petals spirally twisted. The fruits are somewhat globular, slightly fleshy and have a diameter of 4$5 \mathrm{~cm}$. The fruits, which are green in colour, become black on ripening (Figure 1). Each fruit contains a nut which is longitudinally and transversely divided.

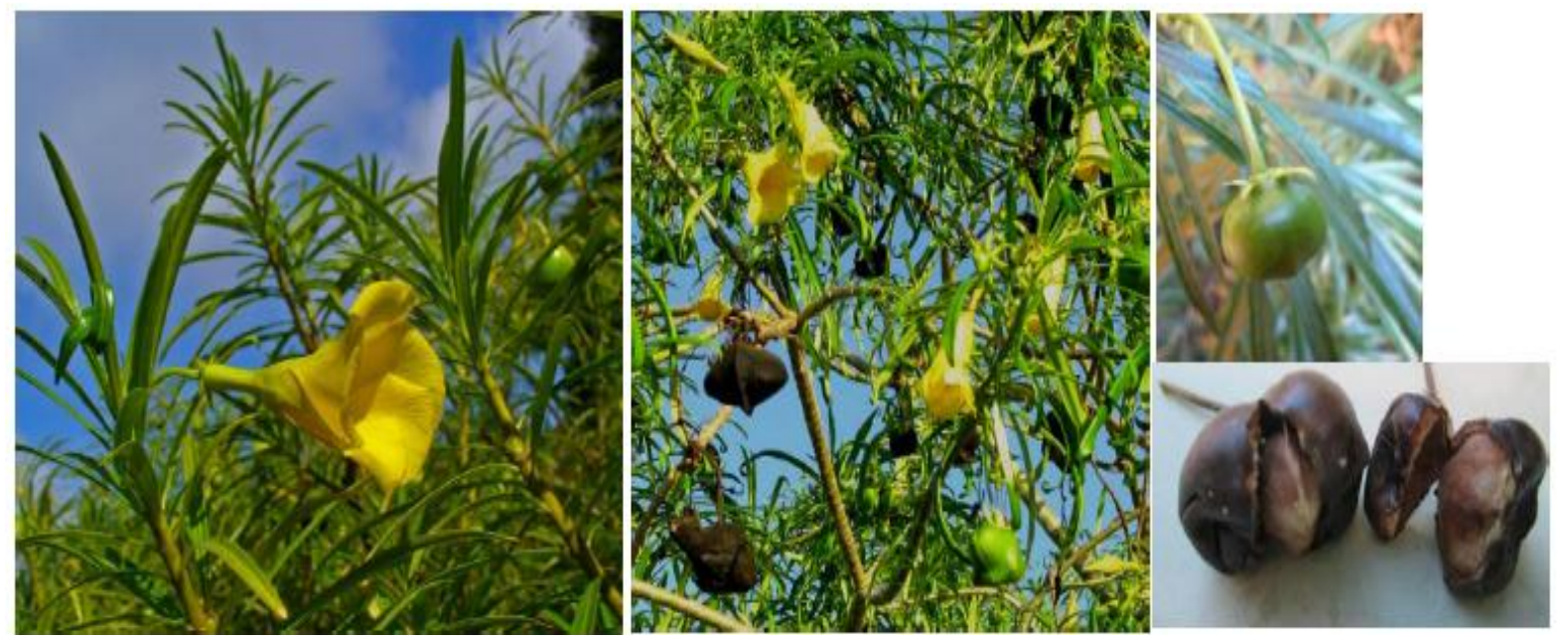

Figure1. Habitat of Yellow Oleander

Thevetia peruviana can be an invasive in open areas and under light shade. T. peruviana has been included in the Global Invasive Species Database [13], but not considered as an invasive species in Sri Lanka.

\subsection{Classification of Yellow Oleander}

Kingdom - Plantae

Class - Magnoliopsida

Order - Gentianales

Family - Apocyanaceae

Genus - Thevetia

Species - Thevetia peruviana (Syn: Cascabela thevetia)

\section{OBJECTIVES}

Yellow oleander seed poisoning (YOSP) is frequent because of suicide attempt and accidental intake. The YOSP is mainly caused by the ingestion of seeds. The study mainly focussed to find relationship between the fruiting pattern of the Yellow oleander and the YOSP, if any where very few/no studies have been conducted to find such relation between them. Therefore, this study is an attempt to find relation between the YOSP and fruiting season of yellow oleander.

\section{MATERIALS AND MeTHODS}

The study was carried out from December 2011 to March 2016 (52 months). Temperature and rainfall were obtained from the Department of Meteorology for the entire period of study. Yellow oleander was noted for the presence of fruits throughout the year 2014 and 2015, both dry and rainy seasons.

The data, both primary and secondary, was obtained from the available records and admitted patients at the Teaching Hospital, Batticaloa regarding yellow oleander poisoning. Randomly selected YOSP patients were interviewed after their recovery. 
Yellow Oleander (Thevetia peruviana) Seed Poisoning (YOSP) in the Batticaloa District, Sri Lanka: Is related with Fruiting Season?

\section{RESUlTS AND DISCUSSION}

\subsection{Temperature and Rainfall of the Study Period}

Eastern Province, in general, experiencing North-East monsoon rainfall during October to end of January or February (Figure 2). It experiencing long dry period afterwards. Both temperature and rainfall show a common pattern for each year, except the rainfall in the early part of the year 2011 and 2013 where flood incidences recorded at the Batticaloa district [14].
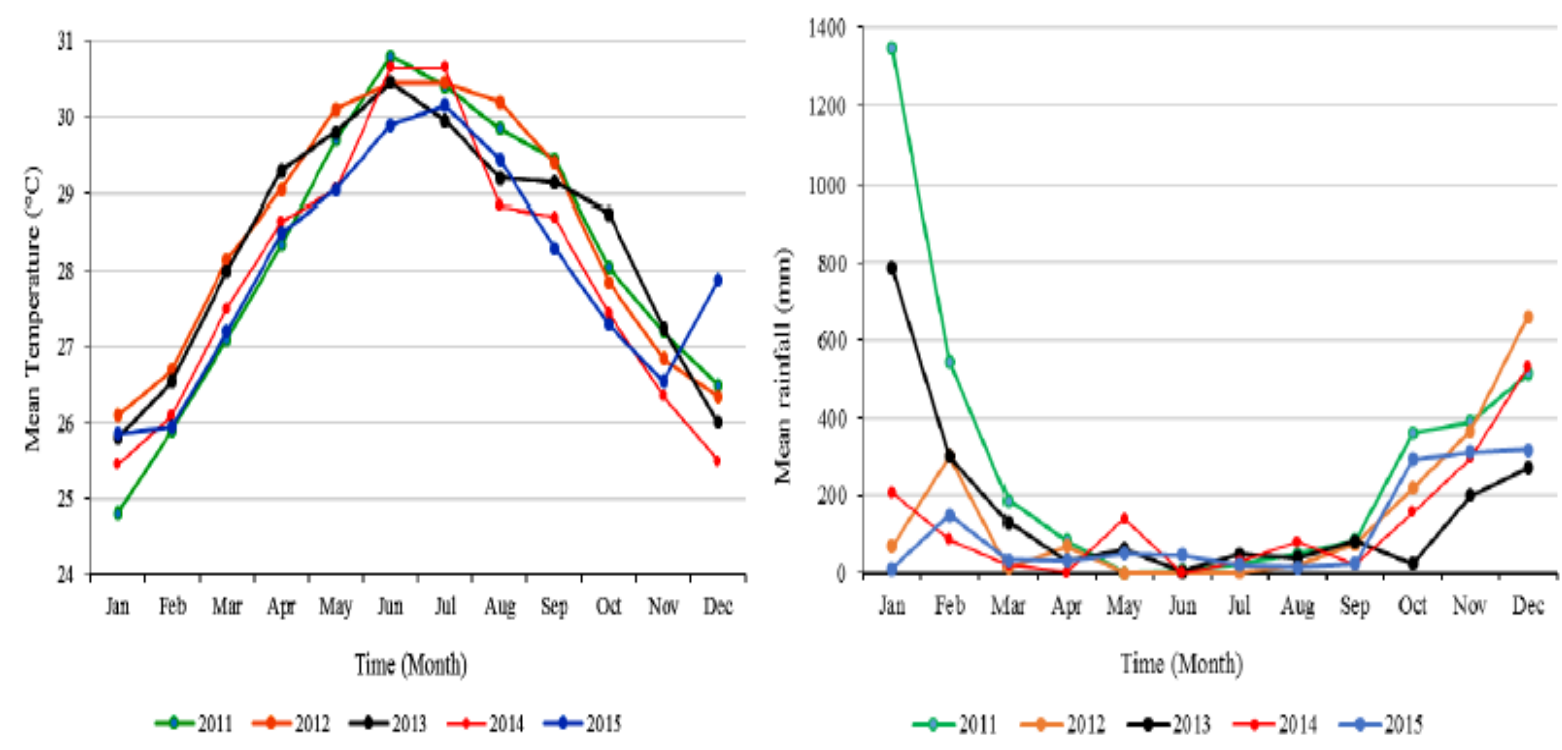

Figure2. Variation in temperature (left) and rainfall (right) for five consecutive years. Year 2016 is not included due to availability of data for three months

\subsection{Yellow Oleander Seed Poisoning (YOSP)}

There were 1076 patients had been admitted due to YOSP at the Teaching Hospital, Batticaloa between November 2011 and March 2016 (during 52 months). Higher percentage of admission was recorded in 2013, followed both by 2012 and 2014 (Figure 3). The results further shown that the incidence of YOSP was fluctuating throughout the year. The average admission was 21 patients per month, ranging from $6-36$ patients. In general, higher percentage of admission was recorded in May when comparing with other months of a year (Figure 4).

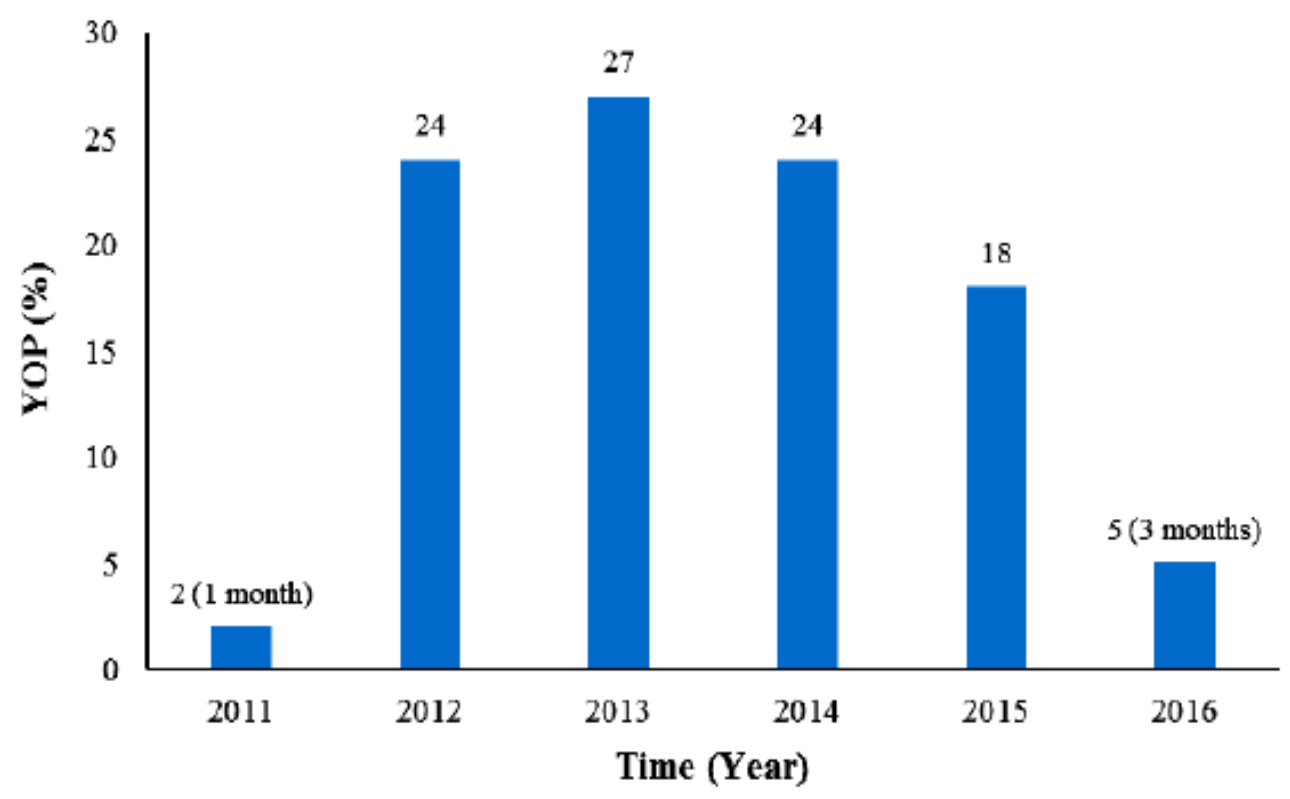

Figure3. Yellow oleander seed poisoning over time in Batticaloa district. Year 2011 and 2016 represent limited months of one and three respectively 
Year 2012

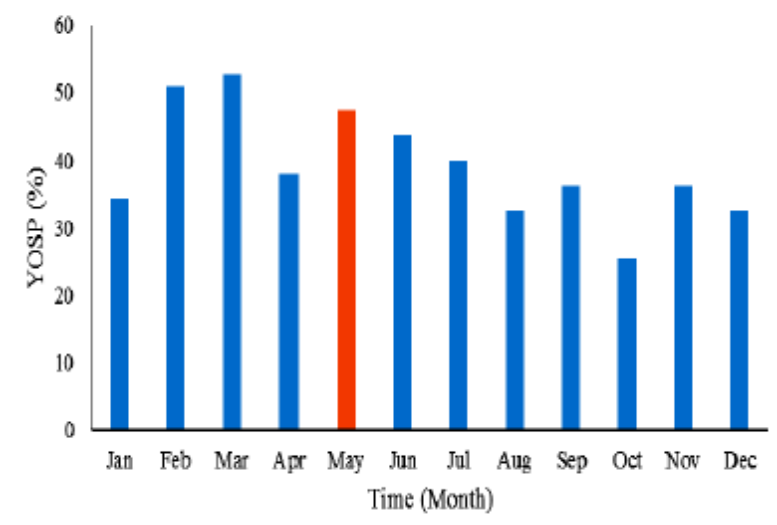

Year 2014

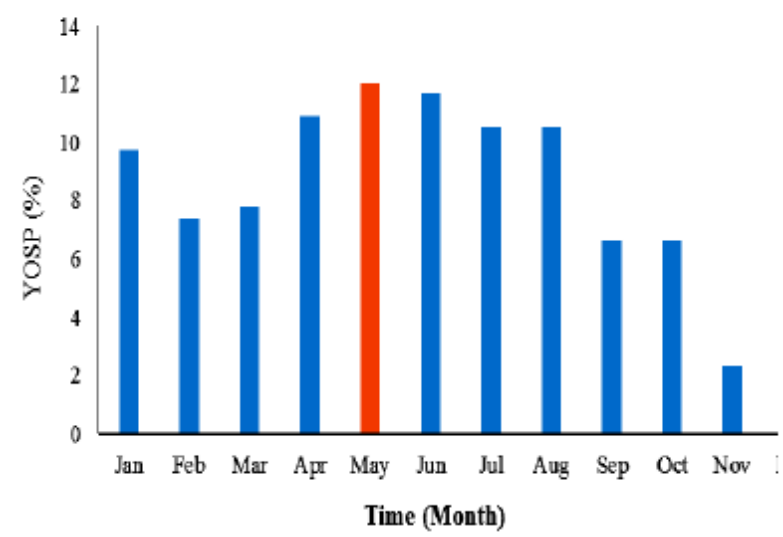

Year 2013

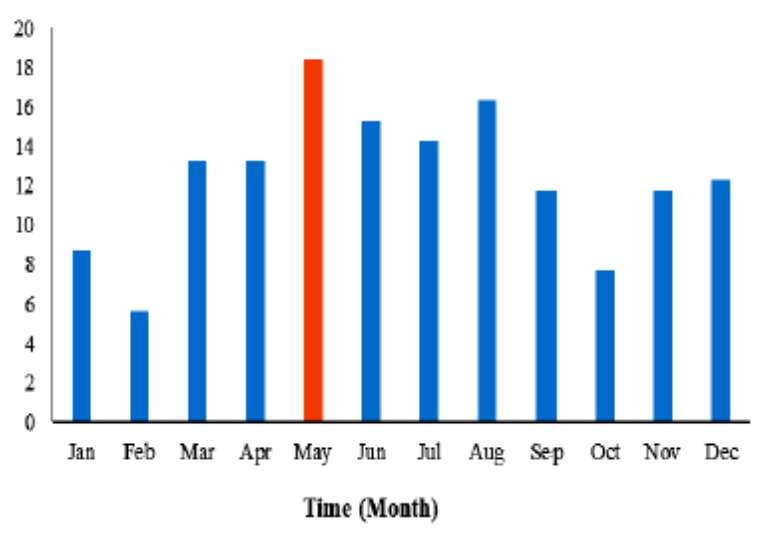

Year 2015

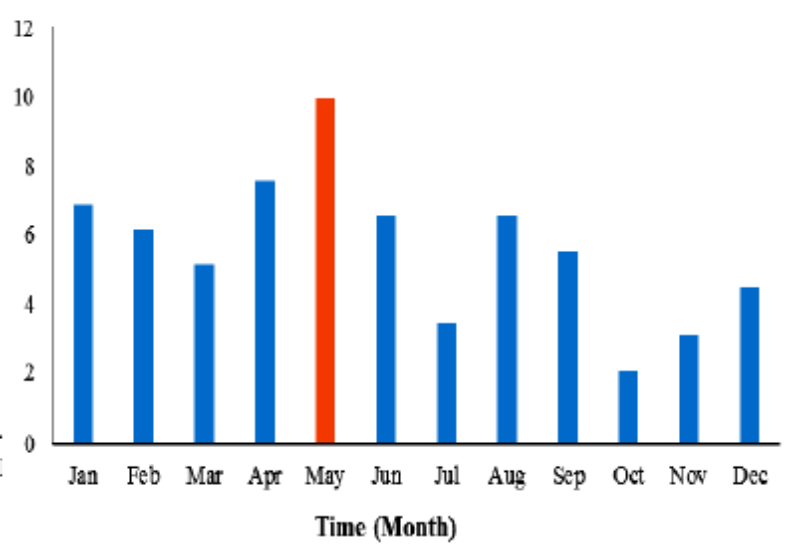

Figure4. Percentage of Yellow oleander seed poisoning in four consecutive years. Higher percent of YOSP noticed in May. Years 2011 and 2016 were not considered due to not including the entire year.

More than $80 \%$ females were admitted due to YOSP with the age range between 20 and 35 years old who committed for suicide (intended intake). This finding also supported by other researchers too [15],[7],[10]. Eddleston et al. [7] reported that about $60 \%$ of the patients were female where a study conducted to find out the YOSP in search of antidote, in the Anuradhapura district, Sri Lanka.

The results show that YOSP is higher during the dry season where the rainfall was below $400 \mathrm{~mm}$ during the study period (Figure 5). This finding is supported by Palangasingahe et al. [16] that "the highest number of admission 1432 (40.38\%) and highest monthly average admissions (57) were observed when rainfall is below $50 \mathrm{~mm}$ and the highest number of deaths (117/147) had occurred when the rainfall was below $150 \mathrm{~mm}$ " in Sri Lanka due to yellow oleander seed poisoning.

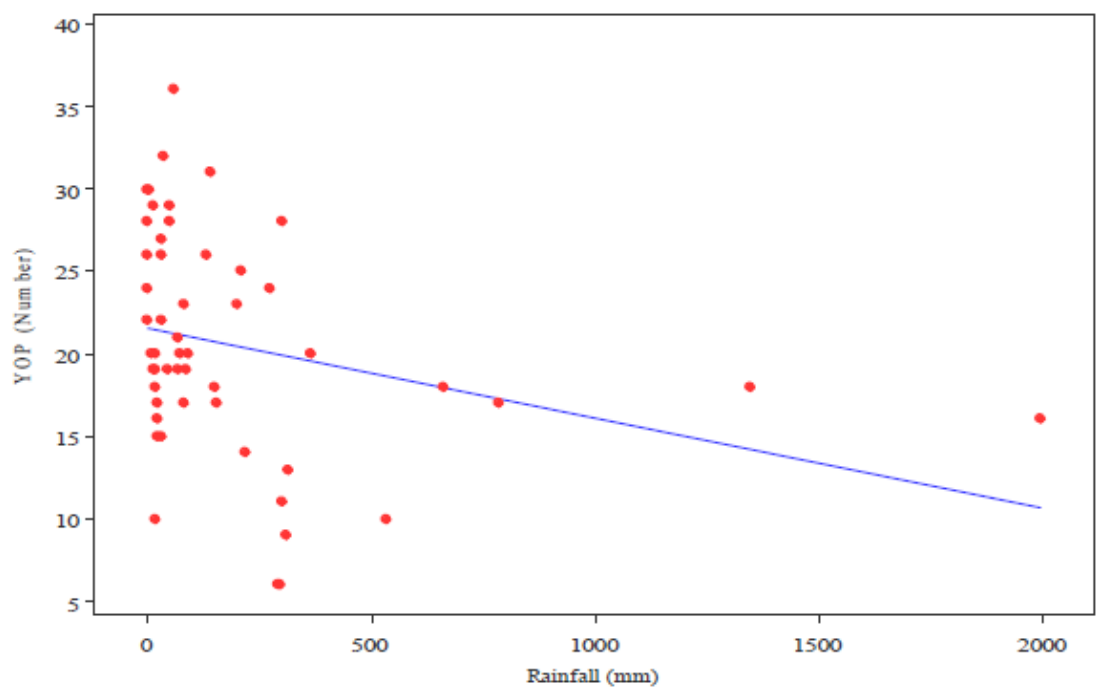

Figure5. YOSP is high during less rainfall period or dry season of a year 
The study unable to establish a relationship between fruiting season of yellow oleander and the YOSP, because yellow oleander produces fruits throughout the year, irrespective of the dry and rainy seasons. Palangasingahe et al. [16] reported that the "rainfall influenced the number of oleander poisoning admissions but was not clearly related to mortality or need for pacing". There are possibilities that during dry season, the concentration of chemical constituents in the seeds may high, which leads more possibility to lethal effects.

Ingestion of seeds produces a clinical picture very similar to that of digoxin [7]. The seeds are highly irritant to the gastrointestinal tract, inducing persistent vomiting and diarrhoea in severe cases. The combination of alcohol and seeds both of which can induces vomiting may explain why intoxicated men were rarely found to be seriously poisoned [7]. But in the case of women they ingest opened, crushed seeds mixed with sugar/sweet or in liquid form, which induces the quick absorption and may leads to lethal.

Interviews with recovered patients revealed that socio-economic problems are the root cause for committing suicide. One of the main reasons is negative life events having ended an emotional relationship such as fail to pass in G.C.E (O/L) (results are released during March/April), lost love and marriage, very few due to unemployment and accidental intake. The finding is supported by a study conducted by Kisokanth et al [17] in the Batticaloa district that conflicts with others (75\%) was the most common risk factor for suicidal attempt. They further reported that $30 \%$ of the suicidal attempts due to YOP.

The second reason is the poverty. More than $90 \%$ of the patients those who admitted due to YOSP were from the western part of the Batticaloa district. Majority of the poor people who are living in the same area, under poverty. It was reported that several teenage widows committed to suicide due to poverty [18]. It is evident the report from Department of Census and Statistics [19] that the Poverty head count ratio of Batticaloa district was 20.3 in the year 2009/10, which is the highest among all the districts of Sri Lanka.

\section{Conclusion}

Yellow oleander seed poisoning (YOSP) is one of the means for committing suicide in the Batticaloa district. Higher percentage of patients are women, under the age of 35 years. Results show that YOSP was higher during dry season, especially in May. The study unable to establish a relationship between fruiting season of yellow oleander and the YOSP, because yellow oleander produces fruits throughout the year, irrespective of the dry and rainy seasons.

\section{REFERENCES}

[1] Fonseka, M.M., Seneviratne, S.L., De Silva, C.E., Gunatilake, S.B. and De Silva, H.J., Yellow oleander poisoning in Sri Lanka: outcome in a secondary care hospital, Human and Experimental Toxicology, 21(6):293-5 (2002).

[2] Kishan, S., Krishnakumar, A., Vimlesh, M., Mubeen, U.S. and Alok, S., A review on: Thevetia peruvina. International Research Journal of Pharmacy, (3)4: 74-77 (2012).

[3] Roberts, D.M., Southcott, E., Potter, J.M. and Buckley, N.A., Pharmacokinetics of digoxin crossreacting substances in patients with acute yellow oleander (Thevetia peruviana) poisoning, including the effect of activated charcoal. Therapeutic Drug Monitoring, 28(6), 784-792 (2006).

[4] Rajapakse, S., Management of yellow oleander poisoning. Clinical Toxicology, 47(3), 206-212 (2009).

[5] Bandara V., Scott, A. Weinsteina, Whitea, J., and Eddleston, B., A review of the natural history, toxinology, diagnosis and clinical management of Nerium oleander (common oleander) and Thevetia peruviana (yellow oleander) poisoning. Toxicon 56(3), 273-281 (2010).

[6] Ibiyemi, S.A., Fadipe, V.O., Akinremi, O.O. and Bako, S.S., Variation in oil composition of Thevetia peruviana Juss 'Yellow Oleander' fruit seeds. Journal of Applied Sciences and Environmental Management, 6(2), 61-65 (2002).

[7] Eddlestan, M., Ariyaratnam, C. A., Meyer, W. P., Perera, G., Kularatne, A. M., Attapattu, S., Sherif, M.H.R and Warrell, D.A., Epidemic of self-poisoning with seeds of the yellow oleander tree (Thevetia peruviana) in northern Sri Lanka. Tropical Medicine and International Health, 4(4), 266-273 (1999). 
[8] Puvaneswaralingam, S., Yellow oleander poisoning and suicide in Sri Lanka, Sottish University Medical Journal, Dundee (online), Healthcare Student Journal of Scotland (2012).

[9] Pirasath, S. and Arulnithy, K., Yellow oleander poisoning in eastern province: an analysis of admission and outcome. Indian Journal of Medical Sciences, 67(7-8), 178-183 (2013).

[10] Rezvi,nS., Yellow Oleander poisoning - in search of antidote. Sri Lanka Medical Association Oration (1999).

www.http://archive.cmb.ac.lk/research/bitstream/70130/589/1/94-1999.pdf, accessed on 18.05. 2016.

[11] Barceloux, D.G., Medical Toxicology of Natural Substances. A John Wiley \& Sons Publication, 854-855 (2008).

[12] Samal, K.K., Sahu, H.K. and Gopalakrishnakone, P., Clinico-pathological study of Thevetia peruviana (yellow oleander) poisoning. Journal of Wilderness Medicine, 3(4): 382-386 (1992).

[13] GISD, Global Invasive Species Database online data sheet. Thevetia peruviana (tree) (2010). www.issg.org/database. Accessed March 2011.

[14] Mathiventhan, T. and Jayasingam, T., Impact of flood on Rhizophora plantation in Batticaloa, Sri Lanka. Journal of Medical and Bioengineering, Engineering and Technology Publishing, (3) 2: 117-121 (2014).

[15] Pirasath, S. and Arulnithy, K., Yellow oleander poisoning in Eastern Province: An analysis of admission and outcome. Indian Journal of Medical Sciences, 67(7), 178-183 (2013).

[16] Palangasinghe, C., Senarathna, L. and Dawson, A.H., Effect of seasonal variation (rain) upon mortality from yellow oleander seeds poisoning. Journal of Medical Toxicology, 4(3), 214 (2008).

[17] Kisokanth, G., Najeem, M.M, and Karunakaran, K. E., The influence of common risk factor for the patients with attempted suicide hospitalized at the Teaching Hospital, Batticaloa. Proceedings, $4^{\text {th }}$ International Symposium, South Eastern University of Sri Lanka, 441-445 (2014).

[18] TamilNet, Poverty driving people to suicide - study (1997), TamilNet, Friday, 17 October 1997, 23:59 GMT).

[19] Department of Census and Statistics, Poverty indicators, Household Income and Expenditure Survey - 2009/10, Ministry of Finance and Planning, Sri Lanka, 1(2) (2011). 